\title{
Factores ambientales asociados con los días no-productivos de cerdas en el trópico mexicano
}

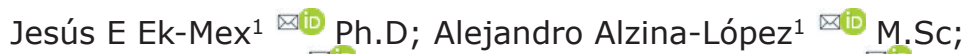 \\ Erika Reyes-González ${ }^{1 凶}$ M.Sc; José C. Segura-Correa ${ }^{1 *} \bowtie(0)$ Ph.D.
}

${ }^{1}$ Universidad Autónoma de Yucatán, Campus de Ciencias Biológicas y Agropecuarias, Km 15.5 carretera Mérida-Xmatkuil, Mérida, Yucatán, México.

*Correspondencia: jose.segura52@hotmail.com

Recibido: Abril 2019; Aceptado: Julio 2019; Publicado: Diciembre 2019.

\section{RESUMEN}

Objetivo. Estimar el número de días no productivos (DNP) de por vida, la proporción de DNP (\%DNP) y días no productivos por cerda por año (DNP/Y), y determinar el efecto de factores de hato y cerda sobre las características aquí estudiadas en tres granjas comerciales en el trópico mexicano. Materiales y métodos. Los datos de 6703 cerdas de tres granjas comerciales fueron usados. El modelo que describió las características de interés incluyeron los efectos fijos de granja, año de primer parto, época de primer parto, edad al primer parto, causa de desecho, interacción de año por época y error residual. Resultados. Las medias de DNP de por vida, \%DNP y DNP/Y fueron 64 días, 12\% y 39.3 días, respectivamente. Todos los factores tuvieron efectos significativos $(p<0.01)$ en todas las características. Las cerdas con primer parto a mayor edad y las eliminadas por razones reproductivas tuvieron más DNP en el hato. Además, las cerdas eliminadas en el primer parto tuvieron menor DNP y mayor \%DNP que las cerdas desechadas en partos subsecuentes. Conclusiones. La eliminación temprana de cerdas incrementó la proporción de días no productivos, que a su vez podrían reducir la rentabilidad de las granjas.

Palabras clave: Parto, eliminación, productividad, trópico (Fuente: $C A B$ ).

\section{ABSTRACT}

Objectives. To estimate the lifetime non-productive days (NPD), lifetime proportion of NPD (\%NPD) and non-productive days per sow per year (NPD/Y), and to determine the effect of herd and sow level factors on the traits here studied in three pig farms in the Mexican tropics. Materials and methods. Data from 6703 sows from three commercial farms were used. The model that described the traits studied comprise the fixed effects of farm, year and season of first farrowing, age at first parity, reasons of removal of sows, year $x$ season interaction and the residual error. Results. The means for lifetime NPD, \%NPD and NPD/Y were 64 days, $12.0 \%$ and 39.3 days, respectively. All fixed factors had significant effects $(p<0.01)$ on the characteristics evaluated. Sows having their first parity at an old age and sows culled because of reproductive reasons had the highest lifetime NPD. In addition, sows culled at first parity had lower lifetime NPD and higher \%NPD than sows culled in subsequent farrowing. Conclusions. The early culling of sows increased the percentage of non-productive days, which in turn is expected to reduce the profit of farms.

Keywords: Farrowing, culling, productivity, tropics (Source: CAB). 


\section{INTRODUCCIÓN}

El número de días no productivos (DNP) es un indicador económico importante en los sistemas de producción de cerdos comerciales, porque las cerdas con DNP largos aumentan los costos de mantenimiento, hacen un uso menos eficiente de la infraestructura y el equipo y reducen la rentabilidad. DNP se definen comúnmente como el número de días en que las cerdas no están gestantes, ni en lactancia, lo que se asocia negativamente con la eficiencia reproductiva y la rentabilidad.

Reducir DNP podría mejorar la productividad de la granja cuando se mide como camadas por cerda en un año y los cerdos destetados por cerda por año. En consecuencia, la disminución de DNP de por vida de las cerdas podría resultar en un aumento de lechones producidos por cerda, mejorando los ingresos de la granja, reduciendo los costos de mantenimiento y aumentando la rentabilidad general (1).

La variación en DNP de por vida de las cerdas se ha relacionado con la estación del primer parto, el tamaño y el manejo del hato, el número de partos al momento del sacrificio, la edad al primer parto 0 al apareamiento y las razones del desecho (2-5). Sin embargo, esos estudios se llevaron a cabo para hatos porcinos en condiciones templadas. Se han realizado pocos informes en condiciones tropicales (6), donde existen diferencias importantes en el clima, el manejo y la infraestructura de las granjas. En Brasil, el efecto del número de parto al desecho y las razones de desecho sobre DNP de por vida han sido reportados (6). Sasaki et al (5) encontraron que las cerdas que tuvieron su primer parto a una edad temprana tuvieron la menor media de DNP durante su vida productiva que las cerdas que parieron a edad mayor.

En México, y específicamente en los trópicos, faltan estudios sobre DNP de por vida, la proporción de NPD y los días no productivos por cerda por año y los factores que los afectan. La identificación de los factores asociados a DNP es necesaria para la toma de mejores decisiones en el funcionamiento de las granjas y para adecuar la tecnología utilizada en las granjas de cerdos.

El objetivo de este trabajo fueron estimar DNP de por vida, la proporción de DNP y los días no productivos por cerda por año, así como, determinar el efecto de algunos factores de riesgo de hato y de la cerda sobre esas características en tres granjas en un ambiente tropical subhúmedo en México.

\section{MATERIALES Y MÉTODOS}

Sitio de Estudio. Se utilizó información de tres granjas comerciales típicas, ubicadas en el sureste de México (Península de Yucatán). La Península es una región importante para la producción porcina, con un clima tropical subhúmedo, precipitación promedio anual de $1100 \mathrm{~mm}$, temperatura promedio de $26.6^{\circ} \mathrm{C}$ y humedad relativa promedio de $78 \%$ (7).

Manejo de cerdas. Las tres granjas fueron granjas comerciales de ciclo completo con 3900 , 1200 y 550 cerdas, respectivamente. En las granjas, la reproducción de las cerdas se practicó mediante inseminación artificial; sin embargo, si una cerda no quedaba gestante después de tres inseminaciones sucesivas, se apareaba de manera natural. La detección del estro en los animales se realizó dos veces al día (6:00 y $18: 00 \mathrm{~h}$ ), utilizando un verraco, y las hembras eran inseminadas 12 y 18 horas después de la detección del estro.

A las hembras jóvenes con un peso corporal de aproximadamente $200 \mathrm{~kg}$ se les proporcionó $2.6 \mathrm{~kg} /$ día de alimento comercial con $16 \%$ de proteína cruda, $3000 \mathrm{kcal} \mathrm{EM} / \mathrm{kg}$ y $0.8 \%$ de lisina; mientras que las cerdas adultas con un peso corporal de $300 \mathrm{~kg}$ o más, recibieron $3.2 \mathrm{~kg} /$ día de la dieta comercial. Las hembras de remplazo se obtuvieron de la misma granja. Los animales se vacunaron contra las enfermedades prevalentes en la región, tales como micoplasmosis, leptospirosis, erisipela, parvovirus y pleuroneumonía.

Tipo de estudio y variables. Se realizó un estudio observacional retrospectivo utilizando información de 2010 a 2014. Los datos se capturaron en el software PigCHAMP ${ }^{\circledR}$, utilizando la información de cerdas desechadas o muertas. La información utilizada para este estudio fue el nombre de la granja, el número de identificación de la cerda, la fecha y la edad del primer parto, el número de parto de la cerda, la fecha del parto y el destete, y la fecha y el motivo de desecho.

La permanencia o duración del tiempo productivo de una cerda en el hato (LPL) se calculó como el número de días desde la primera camada hasta la fecha de desecho. El rasgo de días no productivos (DNP) se definió como el número de días en que la cerda no estuvo gestante o no estuvo en lactancia durante su estadía en el hato. DNP acumulados o de por vida se calculó como LPL menos el número total de días que la 
cerda estuvo gestante, y menos el total de días en lactancia (2).

La media de duración de la gestación se tomó como 115 días. DNP/Y se calculó como DNP de por vida entre LPL y luego se multiplicó por 365 días. DNP/Y se calculó para cada cerda que permaneció en el hato durante al menos 1 año (1). La proporción de DNP por cerda (\%DNP) se calculó mediante la fórmula proporcionada por Lucia Jr. et al (2):

$\%$ DNP $=(($ LPL- total de días gestante - total de días en lactancia) x 100)/ LPL.

Análisis de los datos. El modelo estadístico que describió las variables: DNP de por vida y \%DNP, incluyó los efectos fijos de granja $(1,2,3)$, año de primer parto (2010 a 2014), época de primer parto (seca, lluviosa y nortes), número de parto de la cerda al desecho $(1,2,3, \ldots>7)$, grupo de edad de la cerda al primer parto $(\leq 330,331-347$ y $\geq 348$ días), causa de desecho (reproducción, locomoción, producción, enfermedad, edad y varios), interacciones simples significativas y el error residual, $\operatorname{NID}\left(0, \sigma_{\mathrm{e}}^{2}\right)$.

Los modelos estadísticos para DNP/Y fueron similares a los anteriores, pero no se incluyeron los efectos del número de partos al desecho. Los análisis estadísticos se realizaron utilizando procedimientos de modelo lineal general de SAS (8). En los análisis preliminares de los datos, año por temporada fue la única interacción significativa $(p<0.05)$; por lo tanto, se mantuvo en el modelo estadístico final.

\section{RESULTADOS}

Las medias \pm desviaciones estándares para DNP de por vida, \%DNP y DNP/Y fueron $64.8 \pm 51.7$ días, $12.0 \pm 10.3 \%$ y $39.3 \pm 31.7$ días por año, respectivamente. Todas las fuentes principales de variación tuvieron una influencia significativa $(p<0.01)$ en los rasgos estudiados. Las medias de cuadrados mínimos por nivel de factor se presentan en la tabla 1.

Las cerdas en la granja 1 tuvieron las medias más bajas para DNP, \%DNP y DNP/Y, en comparación con las cerdas en la granja 3 que tuvieron el peor desempeño para todas las características. Además, la interacción año por época fue significativa $(p<0.01)$ para los rasgos aquí estudiados (Figuras 1,2 y 3 ). Así que los efectos principales del año y la época no son discutidos.
Las cerdas desechadas al primer parto tuvieron menos DNP de por vida y mayor \%DNP que las cerdas eliminadas en los partos posteriores. Las cerdas que tuvieron su primera camada a una edad avanzada ( $\geq 348$ días) tuvieron medias más altas para todas las características que las cerdas que parieron a una edad temprana. Las cerdas desechadas, debido a razones reproductivas, tuvieron las medias más altas para DNP, \%DNP y DNP/Y; mientras que aquellos eliminados por razones de baja producción y edad tuvieron medias más bajas para todas las características.

Tabla 1. Medias de cuadrados mínimos \pm errores estándares por factor para número de días no productivos (DNP) de por vida, proporción de DNP (\%DNP) y días no productivos por año $(D N P / Y)$ por cerda en tres granjas comerciales en el sureste de México.

\begin{tabular}{|c|c|c|c|c|c|}
\hline Factor & $\mathbf{N}$ & $\begin{array}{c}\text { DNP } \\
\text { (días) }\end{array}$ & \%DNP & $\mathbf{N}$ & $\begin{array}{c}\text { DNP/Y } \\
\text { (días) }\end{array}$ \\
\hline \multicolumn{6}{|l|}{ Granja } \\
\hline 1 & 5241 & $\begin{array}{c}57.0 \\
\pm 1.10^{c}\end{array}$ & $\begin{array}{c}10.3 \\
\pm 0.22^{c}\end{array}$ & 3816 & $\begin{array}{c}37.4 \\
\pm 0.71^{\mathrm{c}}\end{array}$ \\
\hline 2 & 673 & $\begin{array}{c}80.4 \\
\pm 2.12^{\mathrm{b}}\end{array}$ & $\begin{array}{c}13.5 \\
\pm 0.33^{\mathrm{b}}\end{array}$ & 552 & $\begin{array}{c}42.6 \\
\pm 1.21^{\mathrm{b}}\end{array}$ \\
\hline 3 & 789 & $\begin{array}{c}90.0 \\
\pm 2.02^{\mathrm{a}}\end{array}$ & $\begin{array}{c}15.0 \\
\pm 0.31^{\mathrm{a}}\end{array}$ & 578 & $\begin{array}{c}76.0 \\
\pm 1.32^{\mathrm{a}}\end{array}$ \\
\hline \multicolumn{6}{|l|}{ Partos al desecho } \\
\hline 1 & 1068 & $\begin{array}{c}49.6 \\
\pm 1.82^{\mathrm{e}}\end{array}$ & $\begin{array}{c}21.5 \\
\pm 0.32^{\mathrm{a}}\end{array}$ & & \\
\hline 2 & 886 & $\begin{array}{c}64.3 \\
\pm 2.02^{\mathrm{d}}\end{array}$ & $\begin{array}{c}16.4 \\
\pm 0.31^{\mathrm{b}}\end{array}$ & & \\
\hline 3 & 816 & $\begin{array}{c}73.7 \\
\pm 2.01^{\mathrm{c}}\end{array}$ & $\begin{array}{c}13.5 \\
\pm 0.31^{c}\end{array}$ & & \\
\hline 4 & 688 & $\begin{array}{c}80.7 \\
\pm 2.03^{\mathrm{b}}\end{array}$ & $\begin{array}{c}11.6 \\
\pm 0.43^{d}\end{array}$ & & \\
\hline 5 & 713 & $\begin{array}{c}92.6 \\
\pm 2.04^{\mathrm{a}}\end{array}$ & $\begin{array}{c}11.2 \\
\pm 0.41^{\mathrm{d}}\end{array}$ & & \\
\hline 6 & 1968 & $\begin{array}{c}81.6 \\
\pm 2.03^{\mathrm{b}}\end{array}$ & $\begin{array}{c}9.0 \\
\pm 0.32^{\mathrm{e}}\end{array}$ & & \\
\hline$>7$ & 564 & $\begin{array}{c}88.2 \\
\pm 2.31^{\mathrm{a}}\end{array}$ & $\begin{array}{c}6.8 \\
\pm 0.40^{\mathrm{e}}\end{array}$ & & \\
\hline \multicolumn{6}{|c|}{ Edad al primer parto } \\
\hline$\leq 330$ días & 1642 & $\begin{array}{c}74.6 \\
\pm 1.70^{\mathrm{b}}\end{array}$ & $\begin{array}{l}12.7 \\
\pm 0.3^{\mathrm{b}}\end{array}$ & 1189 & $\begin{array}{c}51.5 \\
\pm 1.13^{\mathrm{b}}\end{array}$ \\
\hline 331-347 días & 3297 & $\begin{array}{c}74.3 \\
\pm 1.41^{\mathrm{b}}\end{array}$ & $\begin{array}{l}12.6 \\
\pm 0.2^{\mathrm{b}}\end{array}$ & 2412 & $\begin{array}{c}50.1 \\
\pm 0.90^{\mathrm{b}}\end{array}$ \\
\hline$\geq 348$ días & 1764 & $\begin{array}{c}78.4 \\
\pm 1.21^{\mathrm{a}}\end{array}$ & $\begin{array}{l}13.3 \\
\pm 0.2^{\mathrm{a}}\end{array}$ & 1345 & $\begin{array}{c}54.5 \\
\pm 0.81^{\mathrm{a}}\end{array}$ \\
\hline \multicolumn{6}{|l|}{ Causa de desecho } \\
\hline Reproducción & 1687 & $\begin{array}{c}110 \\
\pm 1.40^{a}\end{array}$ & $\begin{array}{c}20.2 \\
\pm 0.21^{\mathrm{a}}\end{array}$ & 1000 & $\begin{array}{c}76.3 \\
\pm 1.01^{\mathrm{a}}\end{array}$ \\
\hline Locomoción & 1206 & $\begin{array}{c}68.7 \\
\pm 1.60^{c}\end{array}$ & $\begin{array}{c}10.3 \\
\pm 0.33^{c}\end{array}$ & 673 & $\begin{array}{c}49.8 \\
\pm 1.11^{\mathrm{b}}\end{array}$ \\
\hline Producción & 879 & $\begin{array}{c}62 \\
\pm 1.61^{\mathrm{d}}\end{array}$ & $\begin{array}{c}10.1 \\
\pm 0.32^{c}\end{array}$ & 588 & $\begin{array}{c}44.6 \\
\pm 1.12^{\mathrm{c}}\end{array}$ \\
\hline Enfermedad & 489 & $\begin{array}{c}69.4 \\
\pm 2.11^{\mathrm{bc}}\end{array}$ & $\begin{array}{c}12.0 \\
\pm 0.42^{\mathrm{b}}\end{array}$ & 311 & $\begin{array}{c}49.7 \\
\pm 1.40^{\mathrm{b}}\end{array}$ \\
\hline Edad & 2272 & $\begin{array}{c}68.7 \\
\pm 1.92^{c}\end{array}$ & $\begin{array}{c}12.2 \\
\pm 0.30^{\mathrm{b}}\end{array}$ & 2265 & $\begin{array}{c}38.2 \\
\pm 1.03^{\mathrm{d}}\end{array}$ \\
\hline Misceláneos & 170 & $\begin{array}{c}76.3 \\
\pm 3.53^{\mathrm{b}}\end{array}$ & $\begin{array}{c}12.8 \\
\pm 0.61^{\mathrm{b}}\end{array}$ & 109 & $\begin{array}{c}55.4 \\
\pm 2.32^{\mathrm{b}}\end{array}$ \\
\hline
\end{tabular}

abc Medias con diferente superíndice en la misma columna y factor son diferentes $(p<0.05)$ 


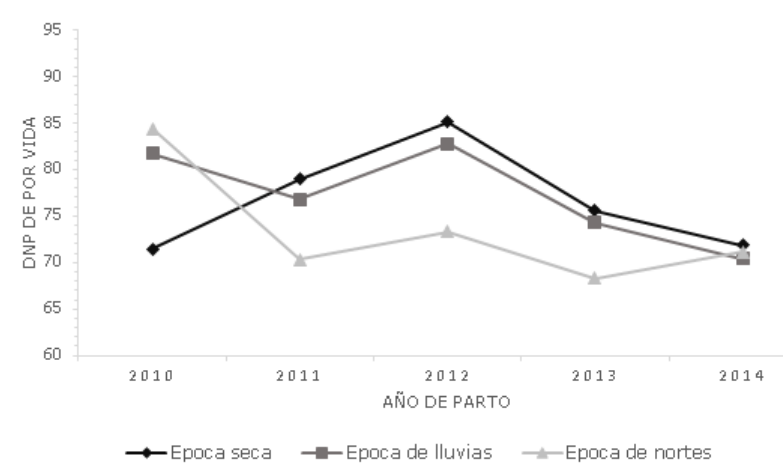

Figura 1. Interacción año por época de parto para número de días no productivos de por vida (DNP) en cerdas.

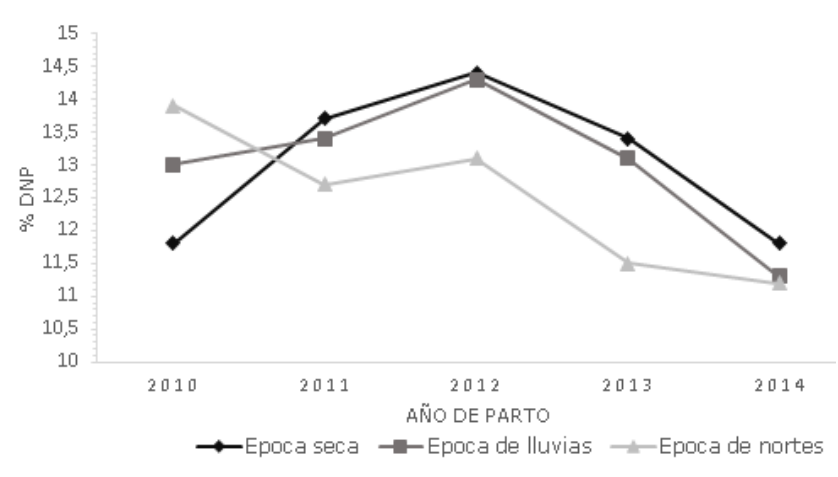

Figura 2. Interacción de año por época de parto para proporción de días no productivos de por vida (\%DNP) en cerdas.

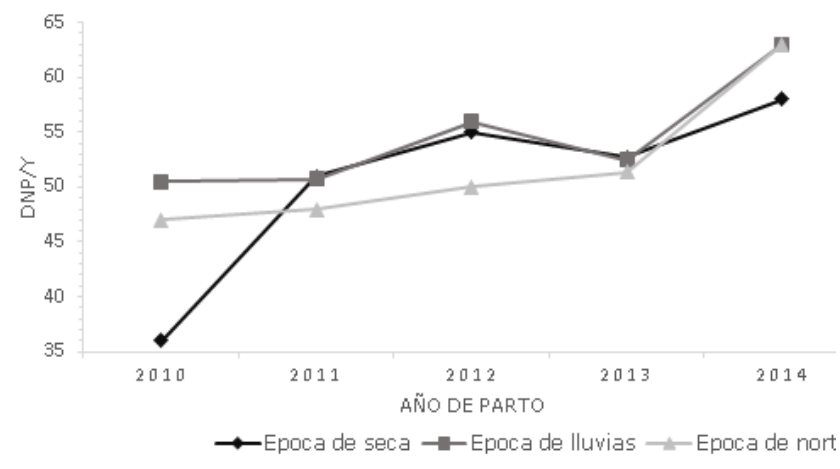

Figura 3. Interacción año por época de parto para días no productivos por cerda por año (DNP/Y) en cerdas.

\section{DISCUSIÓN}

La variable DNP de por vida para las granjas 1 y 2 , estimado aquí, es más bajo que el valor ( 84 DNP) encontrado en Japón (4), aunque la granja 3 tuvo una media más alta. Por otro lado, los promedios de DNP de por vida son más altos que los obtenidos por otros autores en Brasil (6), quienes reportaron 54 DNP durante la vida de las cerdas. Con respecto a \%DNP, Sasaki et al (4) obtuvieron una media de $11 \%$, inferior a la media obtenida en las granjas 2 y 3 . Las medias de DNP/Y para las granjas 1 y 2 fueron inferiores a la media calculada por Lucia Jr. et al (2).

La falta de acuerdo entre los resultados de diferentes estudios o granjas, en DNP de por vida, también podría deberse a diferencias en el tiempo que las cerdas pasan en la granja (9). Del mismo modo, las diferencias en los criterios utilizados para el desecho de una cerda y la forma de calcular esos rasgos pueden explicar los distintos resultados. Algunos estudios definen DNP de por vida como los días desde el nacimiento hasta que la cerda fue removida del hato, mientras que otros, como los días desde la fecha de ingreso al hato reproductivo (o la fecha de primer parto) hasta la remoción. Además, la variación en las medias podría atribuirse a las condiciones climáticas, el manejo y la genética de los cerdos utilizados, incluida la estructura de la población, las medidas de bioseguridad y la prevalencia e incidencia de enfermedades en las granjas.

Babot et al (3), en España, encontraron interacción año por época de partos en DNP acumulados, como en el presente estudio. Esta interacción probablemente esté asociada con un arreglo complejo de condiciones climáticas, estado de salud de los hatos, manejo, alimentación y razones de desecho por año y época.

Las cerdas recibieron alimento comercial que se ajustaba a las necesidades de producción, por lo tanto, las variaciones por año y época pueden estar influenciadas por las temperaturas prevalecientes en cada época, que cambian año con año. Sin embargo, como puede apreciarse en las Figuras 1 a 3, el rendimiento diferente de las cerdas sugiere además que las decisiones de manejo o las causas no identificadas pueden producir un rendimiento diferente por época en cada año. Por lo tanto, la interacción año por época indica que se debe prestar más atención a las cerdas cada año y cada época.

La disminución en DNP y \%DNP en 2013 y 2014 (Figuras 1 y 2) puede deberse en parte al hecho de que, en este estudio, sólo se incluyeron las cerdas desechadas. Además, las medias más bajas para DNP de por vida y $\%$ DNP observados en los últimos dos años de este estudio, pueden deberse a la remoción de cerdas jóvenes. El aumento de DNP/Y podría 
explicarse porque las estimaciones de esta variable, se calcularon considerando sólo a las hembras que permanecieron en el hato durante al menos 1 año, al igual que en el trabajo de Lucia Jr. et al (1).

El efecto del número de parto hasta el desecho sobre DNP de por vida ha sido notificado por Sasaki et al (4) en Japón y Ulguim et al (6) en Brasil. En este estudio, DNP de por vida aumentó con el número de partos por cerda, hasta el parto 5 , como resultado de los DNP acumulados. Sin embargo, \%DNP disminuyó a medida que las cerdas tuvieron más partos, durante su vida en el hato. Esto se asocia al hecho de que las cerdas primíparas tienen el mayor intervalo destete al primer servicio, intervalo de destete a la concepción, un mayor porcentaje de servicios de repetición $(10,11)$ y una menor LPL en comparación con las cerdas multíparas (12). Por lo tanto, prácticas de manejo adecuadas para las cerdas jóvenes y de primer parto podrían garantizar que permanezcan más tiempo en el hato y se reduzcan los costos debido a los reemplazos.

Sasaki et al (5) observaron influencia de la edad al primer parto sobre DNP de por vida en Japón. Sin embargo, Saito et al (13), en el mismo país, no encontraron influencia significativa de la edad al primer parto sobre DNP acumulado. Esto podría deberse a las diferentes prácticas de manejo de las primerizas, como el tipo de detección del estro, la detección temprana y precisa de la gestación, la tasa de crecimiento durante el período de crianza y la genética animal utilizada. Además, es importante considerar el peso óptimo y la condición corporal de las cerdas para mejorar el rendimiento reproductivo en partos posteriores (14). El efecto favorable de la edad temprana al primer parto sobre la productividad también se ha informado en otras especies domésticas como el ganado. Sin embargo, para garantizar la permanencia de las hembras en el hato, debe garantizarse el peso óptimo y el desarrollo del tracto reproductivo.

Ulguim et al (6) y Sasaki et al (5) señalan que las cerdas sacrificadas por problemas reproductivos tuvieron más días no productivos que las cerdas eliminadas por otras razones. Sasaki et al (5) informaron que las cerdas desechadas por problemas reproductivos se eliminaron a una edad temprana, tuvieron menos partos hasta el desecho y tuvieron un número total menor de lechones nacidos vivos durante su estancia en el hato.

Sasaki y Koketsu et al (15), por otro lado, observaron que la principal razón para el desecho estuvo asociada con problemas reproductivos de las cerdas. En Brasil, Lucia Jr. et al (2) encontraron que las cerdas desechadas por la edad avanzada y baja producción menos días no productivos en comparación con las cerdas desechadas por otros motivos; resultados similares a los de este estudio. Esto tiene sentido, ya que la mayoría de los problemas reproductivos están asociados con problemas a la concepción que son las causas principales de desecho de las cerdas (16).

En conclusión, la granja, el número de partos hasta el desecho, la edad al primer parto, la causa de desecho y la interacción año por época tuvieron efectos significativos en las características aquí estudiadas, lo que indica la importancia de estos factores. Las cerdas desechadas a edades tempranas tuvieron menos DNP de por vida y en consecuencia más \%DNP. Por lo tanto, se debe prestar más atención a las cerdas de paridad con el fin de garantizar que permanezcan más tiempo en el hato y sean más productivas. Las cerdas que tuvieron su primer parto $\geq 348$ días y eliminadas por razones reproductivas tuvieron más DNP y DNP/Y; por lo tanto, se deben establecer mejores prácticas de manejo para garantizar que las hembras primerizas alcancen el peso corporal adecuado y el desarrollo de los órganos reproductivos para quedar preñadas lo antes posible.

\section{Conflicto de intereses.}

Los autores del presente estudio declaramos que no existe conflicto de intereses con la publicación de este manuscrito.

\section{Agradecimientos}

Los autores desean reconocer a los propietarios de las granjas por las facilidades proporcionadas para obtener los datos para este estudio. 


\section{REFERENCIAS}

1. Lucia Jr. T, Dial G, Marsh WE. Lifetime reproductive and financial performance of female swine. J Am Vet Med Assoc. 2000; 216:1802-1809. DOI: https://doi. org/10.2460/javma.2000.216.1802 _

2. Lucia Jr. T, Dial G, Marsh WE. Lifetime reproductive performance in female pigs having distinct reasons for removal. Livest Prod Sci. 2000; 63:213-222. DOI: https:// doi.org/10.1016/S0301-6226(99)00142-6

3. Babot D, Chavez ER, Noguera J. The effect of age at first mating and herd size on the lifetime productivity of sows. Anim Res. 2003; 52:49-64. DOI: https://doi. org/10.1051/animres:2003001

4. Sasaki Y, Takemura Y, Koketsu Y. An assessment of four components of sow lifetime nonproductive days and lifetime performance on high-, intermediate- and low-performance commercial breeding farms. J Vet Epidemiol. 2012; 16:135-141. DOI: https://doi.org/10.2743/jve.16.135

5. Sasaki $Y$, Tokunaga T, Uemura R, Sueyoshi $M$. An assessment of reproductive and lifetime performance of Kgoshima Berkshire gilts and sows. Anim Sci J. 2014; 85:213218. https://doi.org/10.1111/asj.12140

6. Ulguim R, Bianchi I, Lucia JrT. Female lifetime productivity in a swine integration system using segregated gilt development units. Trop Anim Health Prod. 2014; 46: 697-700. $\mathrm{h}$ ttps://doi.org/10.1007/s11250014-0546-0

7. Instituto Nacional de Estadística y Geografía (INEGI). Anuario Estadístico de los Estados Unidos Mexicanos 2010. Aguascalientes, Ags: INEGI; 2010.

8. SAS. Statistical Analysis Software, SAS/ STAT, Versión 9.3 edition. Cary (NC): SAS Institute Inc; 2011.

9. Segura-Correa J, Ek-Mex J E, Alzina-López A, Magaña-Monforte J, Sarmiento-Franco $L$, Santos-Ricalde R. Length of productive life of sows in four pig farms in the tropics of Mexico. Trop Anim Health Prod. 2011; 43:1191-1194. https://doi.org/10.1007/ s11250-011-9824-2
10. Tummaruk $\mathrm{P}$, Tantasuparuk $\mathrm{W}$, Techakumphu $M$, Kunavongkrit $A$. Influence of repeatservice and weaning-to-first-service interval on farrowing proportion of gilts and sows. Prev Vet Med. 2010; 96:194-200. https:// doi.org/10.1016/j.prevetmed.2010.06.003

11. Segura-Correa J, Herrera-Camacho J, PérezSanchez R, Gutiérrez-Vazquez E. Breed and environmental factors of sows and their repeatabilities in central Mexico. Rev Colomb Cienc Pecu. 2015; 28(1):13-21. URL Available in: http://aprendeenlinea.udea. edu.co/revistas/index.php/rccp/article/ view/324908

12. Soltesz A, Balogh B. Investigation of lifetime performance in Dutch Large White $\times$ Dutch Landrace crossbred sows. Scientific Papers: Anim Sci and Biotech. 2013; 46:72-81. URL Available in: https://spasb.ro/index.php/ spasb/article/view/191/43

13. Saito $H$, Sasaki $Y$, Koketsu Y. Associations between age of gilts at first mating and lifetime performance or culling risk in commercial herds. J Vet Med Sci. 2011; 73(5):555-559. URL Available in: https:// doi.org/10.1292/jvms.10-0040

14. Schenkel AC, Bernardi ML, Bortolozzo, Wentz I. Body reserve mobilization during lactation in first parity sows and its effect on second litter size. Livest Sci. 2010; 132(1-3):165-172. DOI: https://doi. org/10.1016/j.livsci.2010.06.002

15. Sasaki Y, Koketsu Y. Reproductive profile and lifetime efficiency of female pigs by culling reason in high-performing commercial breeding herds. J Swine Health Prod. 2011; 19(5):284-291. URL available in: https://www.aasv.org/shap/issues/v19n5/ v19n5p284.pdf

16. Segura-Correa JC, Ek-Mex E, Alzina-López A, Segura-Correa VM. Frequency of removal reasons of sows in Southeastern Mexico. Trop Anim Health Prod. 2011; 43(8):15831588. https://doi.org/10.1007/s11250$\underline{011-9847-8}$ 